\title{
Pengabdian Masyarakat Workshop Tripartit Kebijakan Super Tax Deduction Pemagangan Pendidikan Vokasional
}

\author{
Yuyun Estriyantoํ, Valiant Lukad Perdana Sutrisno², Taufik Wisnu Sputra², \\ Indah Widiastuti ${ }^{3}$, Suharno ${ }^{4}$, Muhammad Akhyar ${ }^{5}$ \\ ${ }^{1}$ Mechanical Engineering Education Dept., The Faculty of Teacher Training and Education \\ Sebelas Maret University Indonesia \\ ${ }^{2}$ Mechanical Engineering Education Dept., The Faculty of Teacher Training and Education \\ Sebelas Maret University Indonesia \\ ${ }^{3}$ Mechanical Engineering Education Dept., The Faculty of Teacher Training and Education \\ Sebelas Maret University Indonesia \\ ${ }^{4}$ Mechanical Engineering Education Dept., The Faculty of Teacher Training and Education \\ Sebelas Maret University Indonesia \\ ${ }^{5}$ Mechanical Engineering Education Dept., The Faculty of Teacher Training and Education \\ Sebelas Maret University Indonesia
}

Corresponding email: yuyun.e@staff.uns.ac.id

\begin{abstract}
In 2019, the Ministry of Finance issued a Super Tax Deduction policy, a tax incentive provided by the government to businesses/industries involved in vocational education programs, including research and development activities to generate innovation. This program provides a maximum gross income reduction of up to $200 \%$ of the total costs incurred for work practices, apprenticeship, and/or vocational education learning services. This program is designed to encourage establishing a link-and-match between the world of education and industry to improve the quality of human resources produced by the education sector. Two years since its launch, the socialization of this program has not been optimal. Only a handful of industries have taken advantage of this program. Information that does not reach stakeholders causes the program not to run as expected. The tripartite workshop that brings together all stakeholders is expected to be able to share perceptions regarding the nature and technical implementation of the policy.
\end{abstract}

Keywords: super tax deduction; link-and-match; vocational education; apprenticeship. 


\begin{abstract}
ABSTRAK
Pada tahun 2019, Kementerian Keuangan mengeluarkan kebijakan Super Tax Deduction, yaitu insentif pajak yang diberikan pemerintah kepada dunia usaha/industri yang terlibat dalam program pendidikan vokasi, meliputi kegiatan penelitian dan pengembangan untuk menghasilkan inovasi. Program ini memberikan pengurangan penghasilan bruto maksimal sampai dengan $200 \%$ dari jumlah biaya yang dikeluarkan untuk layanan praktik kerja, pemagangan, dan/atau pembelajaran pendidikan vokasi. Program ini didesain untuk mendorong terwujudnya link-and-match dunia pendidikan dan industri untuk meningkatkan kualitas sumber daya manusia yang dihasilkan dunia pendidikan. Dua tahun sejak diluncurkan, sosialisasi program ini belum cukup optimal. Baru segelintir industri saja yang memanfaatkan program ini. Informasi yang tidak sampai kepada pemangku kepentingan menyebabkan program tersebut tidak bisa berjalan sebagaimana yang diharapkan. Workshop tripartit yang menghadirkan semua pemangku kepentingan diharapkan mampu menyamakan persepsi mengenai hakekat dan teknis implementasi kebijakan tersebut.
\end{abstract}

Kata kunci: super tax deduction; link-and-match; pendidikan vokasi; pamagangan.

\title{
PENDAHULUAN
}

Keselarasan dunia pendidikan dengan dunia industri merupakan tantangan bagi semua negara. Konsep keselarasan pendidikan dan dunia industri merupakan sebuah konsep yang berorientasi pada keterserapan lulusan dunia pendidikan di dunia kerja. Oleh karena itu, dari segi kompetensi yang dimiliki lulusan, jumlah lulusan, bahkan lokasi dan waktu dihasilkannya tenaga kerja hendaknya sesuai dengan kebutuhan tenaga kerja oleh dunia industri. Konsep inilah yang kemudian dikenal dengan istilah link-and-match, yaitu terkait dan selaras antara dunia pendidikan sebagai penghasil tenaga kerja dengan dunia industri sebagai pengguna tenaga kerja. Agar tidak terjadi ketimpangan maka dunia pendidikan harus memenuhi aspek kualitas, kuantitas, waktu, dan lokasi kebutuhan tenaga kerja (Slamet, 2014). 
Salah satu program untuk mewujudkan link-and-match tersebut adalah program pemagangan, yaitu siswa atau mahasiswa diterjunkan secara langsung ke dunia kerja agar memperoleh wawasan dan pengalaman belajar nyata di dunia kerja. Namun demikian, kehadiran siswa magang sering kali menjadi beban bagi industri. Siswa magang membutuhkan layanan dan fasilitas namun tidak memberikan andil ekonomis bagi perusahaan. Apalagi jika pemagangan berlangsung cukup singkat. Namun demikian, program pendidikan ini sangat bermanfaat bagi penyiapan tenaga kerja yang memiliki kompetensi sesuai dengan dunia industri. Oleh karena itu, program ini harus dapat berjalan dengan baik. Kementerian Ketenagakerjaan mengatur kegiatan pemagangan ini dengan Peraturan Menteri Ketenagakerjaan No. 6 tahun 2020 tentang Penyelenggaraan Pemagangan di Dalam Negeri (Menteri Ketenagakerjaan RI, 2020).

Dalam kacamata akademik, pemagangan merupakan satu bentuk pembelajaran experiential learning yang berdampak positif dalam pengembangan sumber daya manusia vokasional yang kompeten. Kegiatan pemagangan juga pernah dikonsep dengan sangat kuat dengan peraturan menteri pendidikan dan kebudayaan pada era Wardiman Djojonegoro dengan istilah Pendidikan Sistem Ganda (MoEC, 1997). Namun, konsep yang sangat baik tersebut tidak jelas keberlangsungan dan keberlanjutannya. Saat ini, semua lembaga pendidikan kejuruan, baik pada jenjang SMK, Sekolah Vokasi, dan juga lembaga penghasil guru kejuruan, pasti memagangkan peserta didiknya untuk meningkatkan kompetensi praktek dan wawasan industri peserta didik. Hal ini sejalan dengan berbagai teori pendidikan kejuruan, bahwa pendidikan kejuruan akan efektif jika dididik-latihkan dengan peralatan, keterampilan, dan kebiasaan industri (Prosser \& Ouigley, 1950).

Pada tahun 2019 pemerintah mengeluarkan kebijakan yang dapat mendukung terwujudnya kegiatan pemagangan yang baik dengan mengeluarkan kebijakan Super Tax Deduction. Kebijakan tersebut dimuat dalam Peraturan Menteri Keuangan No. 128/PMK.010/2019 tentang Pemberian Pengurangan Penghasilan Bruto atas Penyelenggaraan Kegiatan Praktik Kerja (Menteri Keuangan RI, 2019). Super Deduction Tax adalah insentif pajak yang diberikan pemerintah pada industri 
yang terlibat dalam program pendidikan vokasi, meliputi kegiatan penelitian dan pengembangan untuk menghasilkan inovasi. Kebijakan ini diharapkan mampu menciptakan iklim positif kegiatan pemagangan sehingga industri tidak seharusnya merasa direpotkan dengan kehadiran peserta magang karena dapat dikonversi menjadi insentif pengurangan pajak.

Dalam kebijakan tersebut, wajib pajak (WP) badan dalam negeri akan mendapatkan pemotongan pajak tergantung pada jenis kegiatan yang dilakukan. Jika WP badan dalam negeri menyelenggarakan kegiatan magang dan sejenisnya, badan usaha itu akan mendapatkan pengurangan penghasilan bruto paling tinggi $200 \%$ dari jumlah biaya yang dikeluarkan untuk kegiatan pembelajaran tersebut. Sedangkan jika WP badan dalam negeri mengadakan kegiatan penelitian dan pengembangan tertentu, badan usaha tersebut akan mendapatkan pengurangan penghasilan bruto paling tinggi sebesar 300\%. Dengan demikian, jumlah penghasilan kena pajak akan berkurang, bahkan bisa Nol.

Hampir dua tahun sejak diluncurkan, sosialisasi program ini belum optimal. Masih sangat sedikit industri dan lembaga pendidikan kejuruan yang mengetahui program super tax deduction. Di antara yang sudah mengetahui tersebut, mayoritas masih belum paham secara detail bagaimana teknis pelaksanaan program tersebut. Saat ini, baru beberapa gelintir industri saja yang telah berhasil mewujudkannya. Informasi yang tidak sampai kepada pemangku kepentingan ini menyebabkan program tersebut tidak bisa berjalan sebagaimana yang diharapkan. Oleh karena itu, berbagai pihak terkait yang meliputi pihak akademisi, bisnis, dan pemerintah perlu duduk bersama untuk mensukseskan program tersebut.

\section{METODOLOGI PENGABDIAN}

Kegiatan pengabdian masyarakat ini ditujukan untuk memberikan sosialisasi kepada pihak terkait, yaitu lembaga pendidikan kejuruan dan industri mitra magang, dan menyamakan persepsi antar stakeholder mengenai program Super Tax Deduction. Kegiatan dikemas dalam bentuk workshop tripartit sehingga semua pihak yang berkepentingan dapat duduk bersama. Jika ada yang kurang benar pemahamannya, ketiga pihak bisa saling menyampaikan. Dengan demikian simpul 
kemacetan program ini bisa diurai. Nara sumber langsung dari Direktorat Jenderal Pajak karena mereka lah yang paling memahami tafsir dari kebijakan tersebut. Di satu sisi, jika ada kesulitan atau kendala yang kurang sesuai dengan kondisi lapangan, maka lembaga pendidikan dan industri bisa menyampaikan secara langsung. Dengan demikian, program pengabdian masyarakat ini dapat diilustrasikan seperti pada Gambar 1.

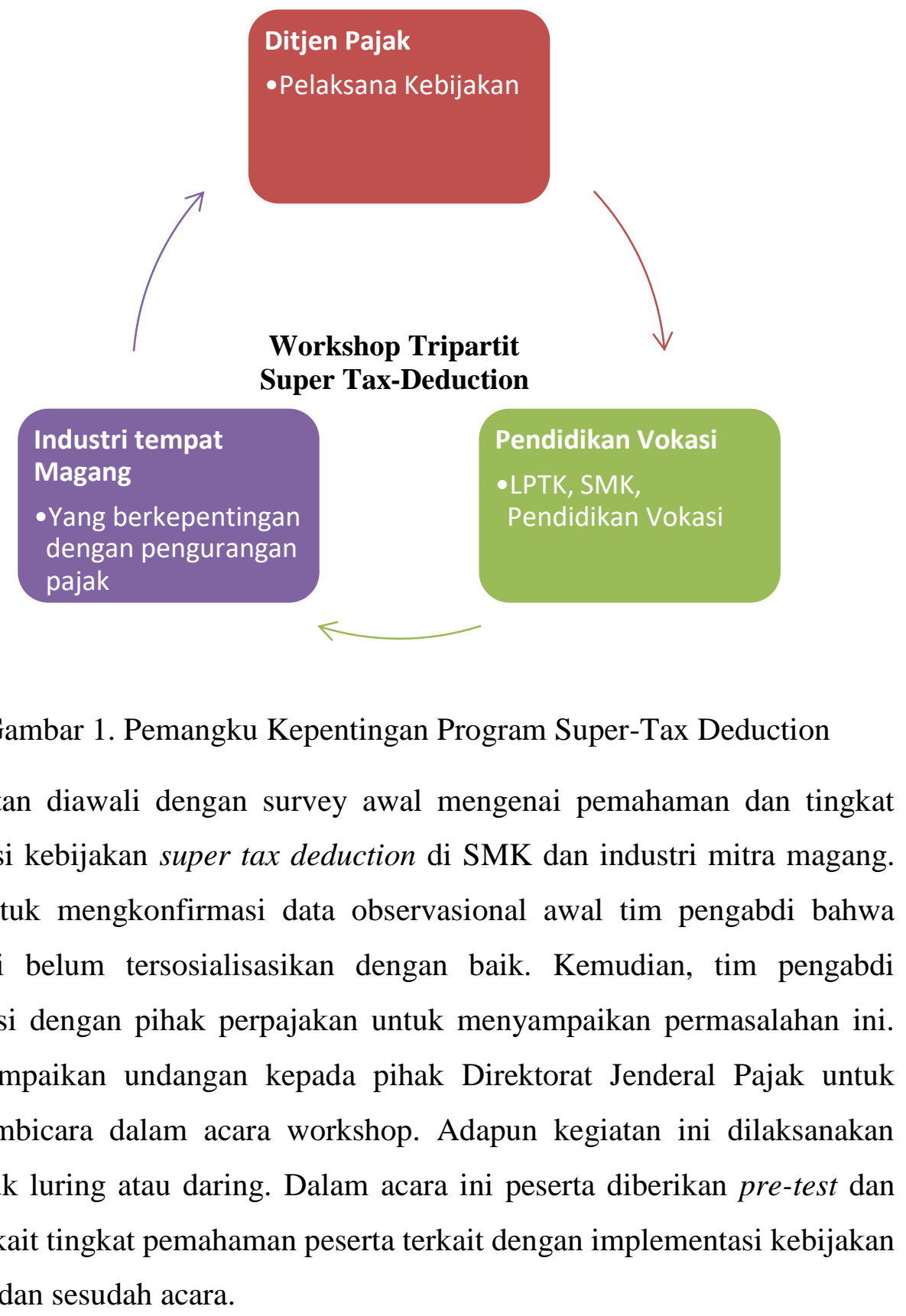




\section{HASIL DAN PEMBAHASAN}

\section{Hasil Pengabdian Masyarakat}

Panitia mengirimkan undangan kepada SMK mitra, LPTK mitra, dan industri mitra magang. Terdapat 33 calon peserta mengisi survey yang diberikan. Dari jumlah tersebut, 60,6\% (20 orang) menyatakan belum mengetahui adanya kebijakan super tax deduction. Dari jumlah tersebut, hanya ada dua yang berasal dari industri. Kedua peserta dari industri tersebut menyatakan belum memanfaatkan insentif pajak. Salah satu calon peserta menyatakan sudah mengetahui, namun sama sekali belum mengetahui prosedur pengurusannya. Sedangkan satu peserta bahkan menyampaikan belum mengetahui sama sekali kebijakan tersebut.

Workshop super tax deduction diselenggarakan secara daring menggunakan media Zoom meeting. Hal ini disebabkan situasi dan kondisi pada saat agenda workshop dilaksanakan bersamaan dengan Pemberlakuan Pembatasan Kegiatan Masyarakat (PPKM) Darurat. Acara telah terlaksana dengan baik pada Hari Senin 5 Juli 2021. Workshop menghadirkan narasumber dari yang berwenang, yaitu Direktorat Jenderal Pajak Kantor Wilayah Jawa Tengah 2 Surakarta. Hadirin berasal dari guru SMK, dosen LPTK Kejuruan, Dosen Politeknik, dan juga praktisi industri. Jumlah paling besar berasal dari guru SMK. Total peserta adalah 36 orang dengan rincian: calon guru SMK (3 orang); dosen LPTK Kejuruan (12 orang); industri (3 orang); dosen politeknik (1 orang); dan guru SMK 17 orang. Sebaran kategori asal peserta disampaikan pada Gambar 2. 


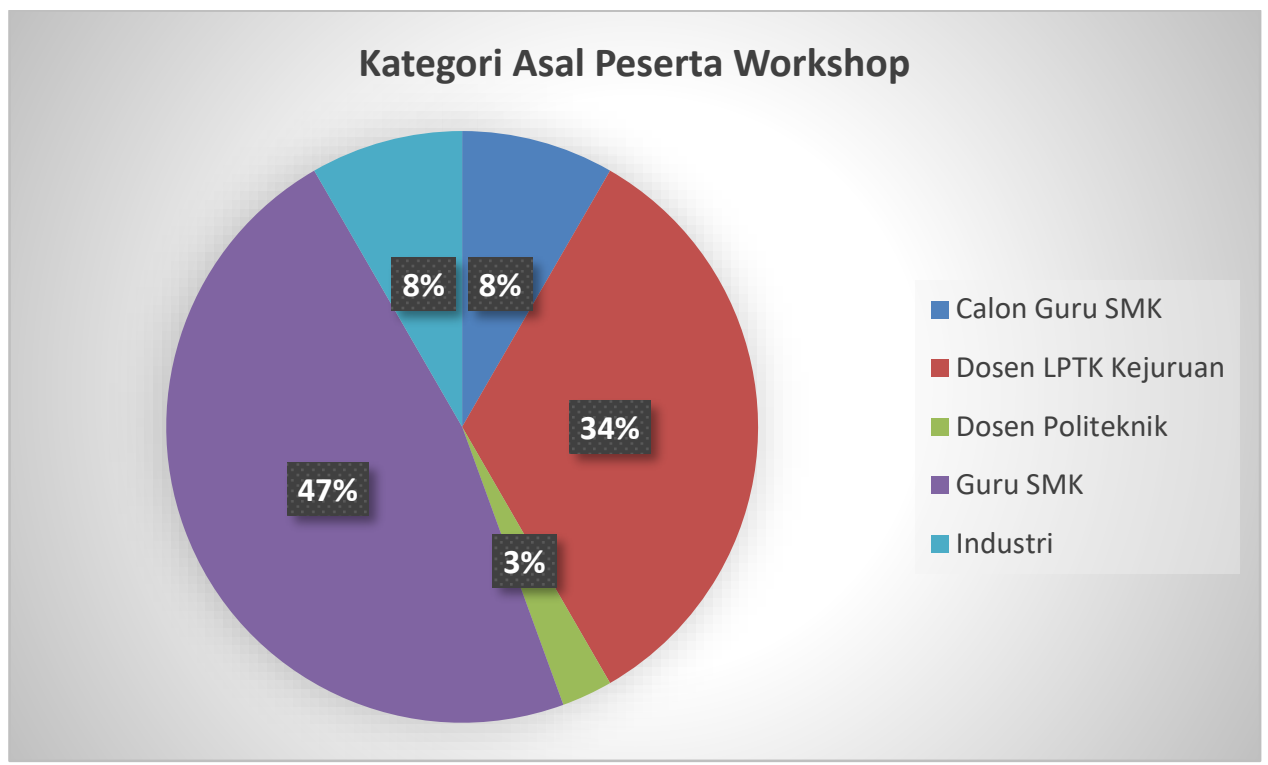

Gambar 2. Kategori Asal Peserta Workshop

Untuk mengetahui keberhasilan penyampaian materi, dilakukan pre-test dan post-test. Soal yang diberikan terkait dengan pemahaman dasar mengenai kebijakan super tax deduction, antara lain: (1) pengetahuan mengenai porsi penerimaan pajak dalam pendapatan negara di APBN Tahun 2021; (2) jumlah alokasi APBN untuk pendidikan sebesar; (3) pengetahuan mengenai manfaat super tax deduction bagi pendidikan vokasi; (4) jumlah maksimal insentif yang diperoleh dari menyelenggarakan program vokasi; (5) pengetahuan dasar tentang jenis biaya yang diperbolehkan sebagai pengurang penghasilan bruto sebagaimana dimaksud dalam PMK 128//PMK.010/2019; (6) pengetahuan tentang OSS; (7) pentehuan tentang pelaporan biaya kegiatan vokasi; dan (8) syarat-syarat pengajuan permohonan Surat Keterangan Fiskal. Untuk peserta yang mengisi pre-test dan post-test dianalisis dengan membandingkan nilai keduanya. Skor rata-rata pre-test adalah 39 sedangkan post-test adalah 60 dari skala 100. Dengan demikian workshop ini cukup berhasil meningkatkan pemahaman peserta terkait dengan kebijakan super tax deduction.

Bersamaan dengan post-test juga diadakan kuesioner untuk menjaring penilaian peserta terhadap efektivitas proses pelaksanaan workshop. Terdapat 10 item closed ended question dalam skala 10. Hasil akhir diperoleh rata-rata skor 8,86 dari skor maksimal 10. Hal ini menunjukkan bahwa penyelenggaraan workshop dan 
penyampaian narasumber berjalan cukup baik dan efektif dalam menyampaikan materi. Hasil evaluasi disampaikan pada Tabel $1 .$.

Tabel 1. Evaluasi Pelaksanaan Workshop

\begin{tabular}{lc}
\hline \multicolumn{1}{c}{ Item Evaluasi } & Skor \\
\hline Penguasaan materi & 8,95 \\
\hline Teknik penyajian materi & 8,68 \\
\hline $\begin{array}{l}\text { Pemberian ilustrasi dan contoh yang dapat membantu memahami } \\
\text { materi }\end{array}$ & 8,53 \\
\hline Pemberian motivasi kepada peserta & 8,63 \\
\hline Kedisiplinan waktu & 9,11 \\
\hline Penampilan & 9,32 \\
\hline Kesesuaian materi dengan tujuan penyuluhan & 9,11 \\
\hline Ketepatan sistematika (urutan) materi & 8,89 \\
\hline Kesesuaian materi dengan alokasi waktu & 8,79 \\
\hline $\begin{array}{l}\text { Kemampuan mengaplikasikan materi setelah menyelesaikan } \\
\text { penyuluhan }\end{array}$ & 8,79 \\
\hline Upaya membantu meningkatkan pengetahuan tentang perpajakan & 8,68 \\
\hline Upaya membantu meningkatkan pemahaman hak perpajakan & 8,89 \\
\hline $\begin{array}{l}\text { Upaya membantu meningkatkan kesadaran melaksanakan } \\
\text { kewajiban perpajakan }\end{array}$ & 8,84 \\
\hline Kelengkapan fasilitas penyuluhan (slide, bahan simulasi, dIII) & 8,89 \\
\hline $\begin{array}{l}\text { Kelengkapan fasilitas pendukung penyuluhan (Aplikasi Zoom, } \\
\text { jaringan internet, pengeras suara, dll) }\end{array}$ & 8,84 \\
\hline Kenyamanan tempat penyuluhan & 8,84 \\
\hline \multicolumn{1}{c}{ Rata-Rata Total } \\
\hline
\end{tabular}

Selain penyampain materi, juga dilaksanakan tanya jawab baik secara langsung maupun melalui chatt box dengan dipandu oleh moderator. Dalam sesi Tanya jawab ini terdapat beberapa pertanyaan, baik untuk memperjelas materi yang disampaikan maupun yang sifatnya lanjut, yaitu tataran implementasi terkait program kerja sama dengan perguruan tinggi yang sudah ada perjanjian kerja samanya (PKS), bagaimanakah teknis jika hendak diajukan ke program insentif pajak.

\section{Pembahasan}

Minimnya industri mitra magang yang hadir dalam kegiatan ini merupakan fenomena yang masih perlu digali. Menurut keterangan narasumber, baru 14 perusahaan yang memanfaatkan insentif pajak ini dari 1,4 juta lebih wajib pajak badan. Fakta rendahnya calon peserta terhadap kebijakan ini mengindikasikan 
bahwa industri mitra magang pun kemungkinan besar juga belum mengetahui kebijakan ini. Karena jika mereka sudah mengimplementasikan insentif pajak ini maka bisa dipastikan SMK juga akan mengetahui hal tersebut karena pasti akan memerlukan PKS yang ditandatangani kedua belah pihak. Peserta dari industri menjadi perhatian khusus karena kebijakan insentif pajak ini pada dasarnya merupakan kebutuhan di sisi industri.

Kegiatan workshop menunjukkan cukup berhasil meningkatkan pemahaman mengenai kebijakan ini. Akan tetapi, hal ini tidak akan berdampak apa-apa jika tidak terjadi domino effect atau diseminasi ke pihak industri. Namun demikian, paling tidak di satu sisi, workshop ini telah memberikan pemahaman kepada pelaku pendidikan kejuruan sebagai pemangku kepentingan pemagangan, yaitu guru-guru SMK, dosen-dosen pada lembaga pendidik tenaga kependidikan kejuruan yang juga berkepentingan memagangkan mahasiswa calon gurunya ke industri, dan juga dosen pada lembaga politeknik yang pada dasarnya paling berkepentingan dengan pemagangan vokasional. Dengan demikian, jika nantinya industri mitra hendak mengajukan PKS untuk implementasi insentif pajak maka dari sisi lembaga pendidikan kejuruan sudah siap.

\section{KESIMPULAN}

Dari uraian di atas dapat disimpulkan bahwa workshop tripartit kebijakan super tax deduction pemagangan pendidikan vokasional dapat meningkatkan pemahaman teknis terkait dengan kebijakan tersebut. Namun demikian, untuk pihak industri masih memerlukan studi yang lebih lanjut mengapa keikutsertaan mereka dalam acara ini rendah, sedangkan industri merupakan pemangku kepentingan utama kebijakan insentif pajak ini. Fakta ini menunjukkan perlunya pendekatan sosialisasi insentif pajak pendidikan vokasi yang berbeda ke industri. Hasil dari workshop ini sebaiknya dikemas dalam bentuk yang lebih handy untuk diberikan langsung ke industri dalam bentuk yang siap saji. Hal ini bisa berbentuk video maupun hardprint dan diberikan langsung ke industri mitra. 


\section{ACKNOWLEDGEMENT}

Artikel ini merupakan laporan kegiatan pengabdian masyarakat yang diselenggarakan oleh group riset Vocational and Mechanical Engineering Education (VMEE), Program Studi Pendidikan Teknik Mesin FKIP UNS di bawah kontrak Lembaga Penelitian dan Pengabdian Kepada Masyarakat (LPPM) UNS No. 261/UN27.22/HK.07.00/2021.

\section{DAFTAR PUSTAKA}

Menteri Ketenagakerjaan RI. (2020). Peraturan Menteri Ketenagakerjaan Republik Indonesia No 6 Tahun 2020 tentang Penyelengaraan Pemagangan di Dalam Negeri.

Menteri Keuangan RI. (2019). Peraturan Menteri Keuangan RI Nomor 128/PMK.010/2019 tentang Pemberian Pengurangan Penghasilan Bruto atas Penyelenggaraan Kegiatan Praktik Kerja, Pemagangan, dan/atau Pembelajaran dalam Rangka Pembinaan dan Pengembangan Sumber Daya Manusia Berbasis Kompete. Kementerian Keuangan Republik Indonesia.

MoEC. (1997). Keputusan Menteri Pendidikan dan Keudayaan RI No 323/U/1997 tentang Pendidikan Sistem Ganda. the Indonesian Ministry of Education and Culture.

Prosser, C. A., \& Ouigley, T. A. (1950). Vocational Education in a Democracy. American Technical Society.

Slamet, P. (2014). Kebijakan Pendidikan Kejuruan: Refleksi Kritis dan Koreksi. Universitas Negeri Yogyakarta. http://staff.uny.ac.id/sites/default/files/pendidikan/slamet-ph-mamedmlhr-drprof/2-kebijakanok.pdf 